THE POTENTIAL DISTRIBUTION THEOREM AND MODELS OF MOLECULAR SOLUTIONS, T. L. Beck, M. E. Paulaitis, and L. R. Pratt (Cambridge University Press, 2006).

\title{
JOURNAL PUBLICATIONS
}

1. D. Chandler and L. R. Pratt, J. Chem. Phys. 65, 2925(1976): "Statistical Mechanics of Chemical Equilibrium and Intramolecular Structures of Nonrigid Molecules in Condensed Phases"

2. L. R. Pratt and D. Chandler, J. Chem. Phys. 66, 148(1977): "Interaction Site Cluster Series for the Helmholtz Free Energy and Variational Principle for Chemical Equilibria and Intramolecular Structures"

3. L. R. Pratt and D. Chandler, J. Chem. Phys. 67, 3683(1977): "Theory of the Hydrophobic Effect"

4. L. R. Pratt, C. S. Hsu, and D. Chandler, J. Chem. Phys. 68, 4202(1978): "Statistical Mechanics of Small Chain Molecules. I. Effects of Liquid Packing on Conformational Structures"

5. C. S. Hsu, L. R. Pratt, and D. Chandler, J. Chem. Phys. 68, 4213(1978): "Statistical Mechanics of Small Chain Molecules. II. Intermolecular Pair Correlations in n-Butane"

6. E. L. Pollock, B. J. Alder, and L. R. Pratt, Proc. Natl. Acad. Sci. USA 77, 49(1980): "Relation Between the Local Field at Large Distance for a Charge or Dipole and the Dielectric Constant"

7. L. R. Pratt and D. Chandler, J. Soln. Chem. 9, 1(1980): "Hydrophobic Interactions and Osmotic Second Virial Coefficients for Methanol in Water"

8. L. R. Pratt, Molec. Phys. 40, 347): "Effective Field a Dipole in Non-Polar Polarizable Fluids"

9. L. R. Pratt and D. Chandler, J. Chem. Phys. 72, 4045(1980): "Effective Intramolecular Potentials for Molecular Bromine in Argon. Comparison of Theory with Simulation"

10. L. R. Pratt, R. O. Rosenberg, B. J. Berne, and D. Chandler, J. Chem. Phys. 73, 1002(1980): "Comment on the Structure of a Simple Liquid Solvent Near a n-Butane Solute Molecule"

11. L. R. Pratt and D. Chandler, J. Chem. Phys. 73, 3430(1980): "Hydrophobic Solvation of Nonspherical Solutes"

12. L. R. Pratt and D. Chandler, J. Chem. Phys. 73, 3434(1980): "Effects of Solute-Solvent Attractive Forces on Hydrophobic Correlations"

13. L. R. Pratt and S. W. Haan, J. Chem. Phys. 74, 1864(1981). "Effects of Periodic Boundary Conditions on Equilibrium Properties of Computer Simulated Fluids. I. Theory"

14. L. R. Pratt and S. W. Haan, J. Chem. Phys. 74, 1873(1981). "Effects of Periodic Boundary Conditions on Equilibrium Properties of Computer Simulated Fluids. II. Applications to Simple Liquids"

15. L. R. Pratt, Molec. Phys. 43, 1163(1981): "Connection Between Central Force Model Treatment of Polyatomic Liquids and the Interaction Site Cluster Expansion"

16. L. R. Pratt, D. L. Ermak, and B. J. Alder, J. Phys. Chem. 85, 3221(1981): "Hard Sphere Solids with One Fluid Component"

17. S. W. Haan and L. R. Pratt, Chem. Phys. Lett. 79, 436(1981): "Monte Carlo Study of a Simple Model for Micelle Structure" [Erratum, Chem. Phys. Lett. 81, 386(1981)].

18. Book Review: "The Hydrophobic Effect: Formation of Micelles and Biological Membranes" J. Am. Chem. Soc. 103, 7697(1981).

19. A. L. Nichols III and L. R. Pratt, J. Chem. Phys. 76, 3782 (1982): "Theory of Surface Structure of Dilute Electrolyte Solutions" 
20. A. L. Nichols III and L. R. Pratt, J. Chem. Phys. 77, 1070(1982): "Slow Decay of Ion Correlations Parallel to an Electrolyte Solution Surface"

21. L. R. Pratt, J. Chem. Phys. 77, 979 (1982): "A New Monte Carlo Method for Direct Estimation of Cluster Partition Functions. Application to Micellar Aggregates"

22. M. A. Wilson, A. L. Nichols III, and L. R. Pratt, J. Chem. Phys. 78, 5129(1983): "Theory of Electrolyte Solution Interfaces at Finite Dilution"

23. A. L. Nichols III and L. R. Pratt, J. Chem. Soc. Faraday Symp. 17, 129(1982): "Disentanglement of Hydrophobic and Electrostatic Contributions to the Film Pressures of Ionic Surfactants"

24. R. A. LaViolette and L. R. Pratt, Phys. Rev. A 28, 2482(1983): "Free Energy of Nucleating Droplets via Cluster-Integral Series"

25. B. Owenson and L. R. Pratt, J. Phys. Chem. 88, 2905(1984): "Molecular Statistical Thermodynamics of Model Micellar Aggregates"

26. A. Pohorille, L. R. Pratt, S. K. Burt, and R. D. MacElroy, J. Biomolec. Struct. Dyn. 1, 1257(1984): "Solution Influence on Biomolecular Equilibria: Nucleic Acid Base Associations"

27. A. L. Nichols III and L. R. Pratt, J. Chem. Phys. 80, 6225(1984): "Salt Effects on the Surface Tensions of Dilute Electrolyte Solutions: Influence of Nonzero Relative Solubility of the Salt between the Coexisting Phases"

28. M. A. Wilson, A. L. Nichols III, and L. R. Pratt, J. Chem. Phys. 81, 579(1984): "Hydrophobic Interaction of Amphiphilic Ions with Water-Hydrocarbon Liquid Interfaces"

29. P. Phillips, R. A. LaViolette, and L. R. Pratt, J. Chem. Phys. 80, 1605(1984): "Multiple Nucleation Pathways Near Triple Points of Ar-Kr Mixtures"

30. B. Owenson and L. R. Pratt, J. Phys. Chem. 89, 6048(1984): "Monte Carlo Calculation of the Molecular Structure of Surfactant Bilayers"

31. R. A. Harris and L. R. Pratt, J. Chem. Phys. 82, 856(1985): "Discretized Propagators, Hartree and Hartree-Fock Approximations, and the Hohenberg-Kohn Theorem"

32. R. A. Harris and L. R. Pratt, J. Chem. Phys. 82, 5084(1985): "Discretized Propagators in Hartree and Hartree-Fock Theory. II. Responses to Static Electric and Magnetic Fields"

33. R. A. Harris and L. R. Pratt, J. Chem. Phys. 83, 4024(1985): "A Method for Systematic Inclusion of Electron Correlation in Density Functionals"

34. L. R. Pratt, Ann. Rev. Phys. Chem. 36, 433(1985): "Theory of Hydrophobic Effects"

35. L. R. Pratt and D. Chandler, Methods in Enzymology 127, 48(1985): "Theoretical and Computational Studies of Hydrophobic Interactions"

36. A. Pohorille and L. R. Pratt, Methods in Enzymology 127, 64(1985): "Theoretical Methods for Obtaining Free Energies of Biomolecular Equilibria in Aqueous Solution"

37. M. A. Wilson, A. Pohorille, and L. R. Pratt, J. Chem. Phys. 83, 5832(1985): "Molecular Dynamics Test of the Brownian Description of $\mathrm{Na}^{+}$Motion in Water"

38. L. R. Pratt, B. Owenson, and Zhewei Sun, Advances in Colloid and Interface Science 26, 69(1986): "Molecular Theory of Micelle Formation in Aqueous Solution"

39. L. R. Pratt, J. Chem. Phys. 85, 5045(1986): "A Statistical Method for Identifying Transition States in High Dimensional Problems"

40. J. Geldard and L. R. Pratt, J. Chem. Ed. 64, 425 (1987): "Statistical Determination of Normal Modes"

41. L. R. Pratt, J. Chem. Phys. 87, 1245 (1987): "Fluctuation Method for the Calculation of Elastic Constants of Solids"

42. M. A. Wilson, A. Pohorille, and L. R. Pratt, J. Phys. Chem. 91, 4873(1987): "Molecular Dynamics of the Water Liquid-Vapor Interface" 
43. A. Pohorille, L. R. Pratt, R. A. LaViolette, M. A. Wilson, and R. D. MacElroy, J. Chem. Phys. 87, 6070 (1987): "Comparison of the Structure of Harmonic Aqueous Glasses and Liquid Water"

44. L. R. Pratt, G. G. Hoffman, and R. A. Harris, J. Chem. Phys. 88, 1818 (1988): "Statistical Theory of Electron Densities"

45. M. A. Wilson, A. Pohorille, and L. R. Pratt, J. Chem. Phys. 88, 3281(1988): "Surface Potential of the Water Liquid-Vapor Interface"

46. G. G. Hoffman, L. R. Pratt, and R. A. Harris, Chem. Phys. Letts. 148, 313 (1988): "Monte Carlo Integration of Density Functional Theory: Fermions in a Harmonic Well"

47. M. A. Wilson, A. Pohorille, and L. R. Pratt, Chem. Phys. 129, 209(1989): "Interaction of a Sodium Ion with the Water Liquid-Vapor Interface"

48. M. A. Wilson, A. Pohorille, and L. R. Pratt, J. Chem. Phys. 90, 5211(1989): "Comment on 'Study on the Liquid-Vapor Interface of Water..."' See also B. Yang, D. E. Sullivan, B. TjiptoMargo, and C. G. Gray, J. Phys. Condens. Matter 3, F109(1991): "Molecular Orientational Structure of the Water Liquid/Vapour Interface"

49. L. R. Pratt and J. Eckert, Phys. Rev. B 39, 13 170(1989): "Molecular Dynamics of a Dilute Solution of Hydrogen in Palladium"

50. L. R. Pratt, Phys. Rev. A 40, 6077 (1989): "Lower Bound on the Ground State Energies of Atoms and Molecules by Variational Quantum Monte Carlo"

51. L. R. Pratt, G. G. Hoffman, and R. A. Harris, J. Chem. Phys. 92, 6687 (1990): "Ground State Densities from Electron Propagators: Optimized Thomas-Fermi Approximation for Short Wavelength Modes"

52. G. G. Hoffman and L. R. Pratt, Proceedings of the International Workshop on Quantum Simulation of Condensed Matter Phenomena, edited by J. D. Doll and J. E. Gubernatis (World Scientific Publishing Co. Pte. Ltd., Teaneck NJ, 1990), pages 105-115: "Optimized ThomasFermi potential for discrete propagator electron density functional calculations"

53. A. Pohorille and L. R. Pratt, J. Am. Chem. Soc. 112, 5066(1990): "Cavities in Molecular Liquids and the Theory of Hydrophobic Solubilities" See also "Simulated Liquids Point to New Solutions," Science News, 7 July 1990, page 5.

54. G. G. Hoffman and L. R. Pratt, Proc. Roy. Soc. A 435, 245(1991). "Statistical Theories of Electron Densities: Multiple Scattering Perturbation Theory"

55. L. R. Pratt, J. Phys. Chem. 96, 25(1991): "Contact Potentials of Solution Interfaces: Phase Equilibrium and Interfacial Electric Fields"

56. L. R. Pratt, CLS Division 1991 Annual Review: "Oil and Water Don't Mix" LA-UR-91-1783. National Technical Information Service, U. S. Department of Commerce, 5285 Port Royal Rd., Springfield, VA 22161.

57. G. G. Hoffman, R. A. Harris, and L. R. Pratt, Can. J. Chem. 70, 478(1992): "Statistical Theory of Electron Densities at Nonzero Temperatures"

58. L. R. Pratt and A. Pohorille, Proc. Nat. Acad. Sci. USA 89, 2995(1992): "Theory of Hydrophobicity: Transient Cavities in Molecular Liquids"

59. D. L. Lynch, J. D. Doll, S. W. Rick, M. A. Gomez, and B. W. Spath, L. R. Pratt, J. Chem. Phys. 97, 5177(1992): "Spectroscopic Studies of Surface and Subsurface Hydrogen/Metal Systems"

60. R. A. Harris and L. R. Pratt, Chem. Phys. Letts. 203, 399(1993): "Simple Effective Hamiltonian for Low-Frequency Responses"

61. L. R. Pratt and A. Pohorille, Proceedings of the EBSA 1992 International Workshop on WaterBiomolecule Interactions, edited by M. U. Palma, M. B. Palma-Vittorelli, and F. Parak (Societá Italiana de Fisica, Bologna, 1993), pp. 261-268: "Hydrophobic Effects from Cavity Statistics"

62. L. R. Pratt and R. A. Keller, J. Phys. Chem. 97, 10254 (1993): "Estimate of the Probability of Diffusional Misordering in High-Speed DNA Sequencing" 
63. G. G. Hoffman and L. R. Pratt, Molec. Phys. 82, 245(1994): "Comparison of Electron Density Functional Models"

64. L. R. Pratt, G. Hummer, and A. E. García, Biophys. Chem. 51, 147(1994): "Ion Pair Potentialsof-Mean-Force In Water"

65. G. J. Tawa and L. R. Pratt in Structure and reactivity in aqueous solution: Characterization of chemical and biological systems, ACS Symposium Series 568, edited by C. J. Cramer and D. G. Truhlar (American Chemical Society, Washington DC, 1994), pp. 60-70: "Tests of Dielectric Model Descriptions of Chemical Charge Displacements in Water"

66. G. J. Tawa and L. R. Pratt, J. Am. Chem. Soc. 117, 1625(1995): "Theoretical Calculation of the Water Ion Product $\mathrm{K}_{W}$ "

67. G. Hummer, L. R. Pratt, and A. E. García, J. Phys. Chem. 99, 14188(1995): "The Hydration Free Energy of Water"

68. G. Hummer, L. R. Pratt, and A. E. García, J. Phys. Chem. 100, 1206(1996): "Free Energy of Ionic Hydration" See also F. Figueirido, G. S. Del Buono, R. M. Levy, J. Phys. Chem. B 101, $5622(1997)$.

69. S. A. Corcelli, J. D. Kress, L. R. Pratt, and G. J. Tawa, Pacific Symposium on Biocomputing '96, edited by L. Hunter and T. E. Klein (World Scientific, Singapore, 1995), pp. 142-159. "Mixeddirect-iterative Methods for Boundary Integral Formulations of Continuum Dielectric Solvation Models"

70. G. J. Tawa, R. L. Martin, L. R. Pratt, and R. V. Russo, J. Phys. Chem. 100, 1515 (1996): "Solvation Free Energy Calculations Using a Continuum Dielectric Model for the Solvent and Gradient Corrected Density Functional Theory for the Solute"

71. S. Garde, G. Hummer, A. E. García, L. R. Pratt, and M. E. Paulaitis, Phys. Rev. E 53, R4310 (1996): "Hydrophobic Hydration: Inhomogeneous Water Structure Near Nonpolar Molecular Solutes"

72. G. Hummer, S. Garde, A. E. García, A. Pohorille, and L. R. Pratt, Proc. Natl. Acad. USA93, 8951 (1996): "An Information Theory Model of Hydrophobic Interactions" See also the commentary B. J. Berne, Proc. Natl. Acad. USA 93, 8800 (1996): "Inferring the hydrophobic interaction from the properties of neat water"

73. S. Garde, G. Hummer, A. E. García, M. E. Paulaitis, and L. R. Pratt, Phys. Rev. Letts. 77 , 4966 (1996): "Origin of Entropy Convergence in Hydrophobic Hydration and Protein Folding" See also comments by S. Marcelja, Biophys. J. 78, 593-594 (1999).

74. L. R. Pratt, G. J. Tawa, G. Hummer, A. E. García, and S. A. Corcelli, Int. J. Quant. Chem. 64, 121(1997): "Boundary Integral Methods for the Poisson Equation of Continuum Dielectric Solvation Models"

75. G. J. Tawa, R. L. Martin, and L. R. Pratt, Int. J. Quant. Chem. 64, 143 (1997): "Reaction Field Spectral Shifts with Semi-Empirical Molecular Orbital Theory"

76. G. Hummer, L. R. Pratt, A. E. García, B. J. Berne, and S. W. Rick, J. Phys. Chem. B 101, 3017(1997): "Electrostatic Potentials and Free Energies of Solvation of Polar and Charged Molecules"

77. G. Hummer, L. R. Pratt, and A. E. García, J. Am. Chem. Soc. 119, 8523 (1997): "Multistate Gaussian Model for Polar and Ionic Hydration"

78. G. Hummer, L. R. Pratt, and A. E. García, J. Chem. Phys. 107, 9275 (1997): "Ion Sizes and Finite-Size Corrections for Ionic-Solvation Free Energies"

79. G. Hummer, S. Garde, A. E. García, M. E. Paulaitis, and L. R. Pratt, Proc. Natl. Acad. USA 95, 1552 (1998): "The Pressure Dependence of Hydrophobic Interactions Is Consistent with the Pressure Denaturation of Proteins"

80. L. R. Pratt, Hydrophobic Effects, in the Encyclopedia of Computational Chemistry, Schleyer, P. v. R.; Allinger, N. L.; Clark, T.; Gasteiger, J.; Kollman, P. A.; Schaefer III, H. F.: Schreiner, P. R., Eds.; John Wiley \& Sons, Chichester, 1998. 
81. R. L. Martin, P. J. Hay, and L. R. Pratt, J. Phys. Chem. A 102, 3565-3573 (1998): "Hydrolysis of Ferric Ion in Water and Conformational Equilibrium"

82. L. R. Pratt and R. A. LaViolette, Molec. Phys. 94, 909(1998): "Quasi-chemical Theories of Associated Liquids"

83. S. J. Paddison, L. R. Pratt, T. Zawodzinski, D. W. Reagor, Fluid Phase Equilibria 150, 235(1998): "Molecular Modeling of Trifluoromethanesulfonic Acid for Solvation Theory"

84. G. Hummer, L. R. Pratt, and A. E. García, J. Phys. Chem. A 102, 7885(1998): "Molecular Theories and Simulation of Ions and Polar Molecules in Water"

85. M. A. Gomez and L. R. Pratt, J. Chem. Phys. 109, 8783(1998): "Construction of Simulation Wavefunctions for Aqueous Species: $\mathrm{D}_{3} \mathrm{O}^{+} "$

86. L. R. Pratt, S. Garde, and G. Hummer, in NEW APPROACHES TO PROBLEMS IN LIQUID STATE THEORY, NATO Science Series 529, edited C. Caccamo, J.-P. Hansen, and G. Stell (Kluwer, Netherlands, 1999), 407-420: "Theories of Hydrophobic Effects and the Description of Free Volume in Complex Liquids"

87. G. Hummer, S. Garde, A. E. García, M. E. Paulaitis, and L. R. Pratt, J. Phys. Chem. B 102, 10469(1998): "Hydrophobic Effects on a Molecular Scale"

88. S. Garde, A. E. García, L. R. Pratt, and G. Hummer, Biophys. Chem. 78, 21-32, (1999): "Temperature Dependence of the Solubility of Nonpolar Gases in Water"

89. S. J. Paddison, L. R. Pratt, and T. A. Zawodzinski, Jr., in Proton Conducting Membrane Fuel Cells II, S. Gottesfeld and T. F. Fuller, Editors, PV 98-27, the Electrochemical Society Proceedings Series, Pennington, NJ (1999), pp 99-105: "Theoretical Structure of Triflic Acid-Water Clusters and the Molecular Mechanism of Proton Dissociation"

90. M. A. Gomez, L. R. Pratt, G. Hummer, and S. Garde, J. Phys. Chem. B 103, 3520-3523, (1999): "Molecular Realism in Default Models for Information Theories of Hydrophobic Effects"

91. S. J. Paddison, L. R. Pratt, and T. A. Zawodzinski, Jr., J. New Mat. Electrochem. Sys. 2, 183-188(1999): "Conformations of Perfluoroether Sulfonic Acid Side Chains for the Modeling of Nafion"

92. B. S. Jorgensen, R. C. Dye, M. A. Gomez, L. R. Pratt, and J. E. Meadows, Fusion Technology 37, 124-130(2000): "Concentrating Low Level Tritiated Water Through Isotope Exchange"

93. L. R. Pratt and S. B. Rempe, Simulation and Theory of Electrostatic Interactions in Solution, AIP Conference Proceedings 492, (1999), eds. L. R. Pratt and G. Hummer, pp. 172-201: "Quasi-chemical Theory and Implicit Solvent Models for Simulations"

94. G. Hummer, L. R. Pratt, A. E. García, and M. Neumann, Simulation and Theory of Electrostatic Interactions in Solution, AIP Conference Proceedings 492, (1999), eds. L. R. Pratt and G. Hummer, pp. 84-103: "Treatment of Electrostatic Interactions In Computer Simulations and Calculations of Thermodynamic Properties Such As Free Energies and Pressures"

95. S. B. Rempe, L. R. Pratt, Gerhard Hummer, J. D. Kress, Richard L. Martin, and Antonio Redondo, J. Am. Chem. Soc. 122, 966-967 (2000): "The Hydration Number of $\mathrm{Li}^{+}$in Liquid Water"

96. G. Hummer, S. Garde, A. E. García, L. R. Pratt, Chem. Phys. 258, 349-370(2000): "New Perspectives on Hydrophobic Effects"

97. S. B. Rempe and L. R. Pratt, Fluid Phase Equilibria, 183-184, 121(2001): "The Hydration Number of $\mathrm{Na}^{+}$in Liquid Water"

98. S. J. Paddison, L. R. Pratt, and T. A. Zawodzinski, Jr., J. Phys. Chem. A 105, 6266-6268(2001): "Variation of the Dissociation Constant of Triflic Acid with Hydration"

99. L. R. Pratt, R. A. LaViolette, M. A. Gomez, and M. E. Gentile, J. Phys. Chem. B 105, 1166211668 (2001): "Quasi-Chemical Theory for the Statistical Thermodynamics of the Hard Sphere Fluid" 
100. L. R. Pratt, Annu. Rev. Phys. Chem. 53, 409-436 (2002): "Molecular Theory of Hydrophobic Effects: "She is too mean to have her name repeated."

101. L. R. Pratt, Chem. Rev. 102, 2625(2002): "Introduction: Water"

102. L. R. Pratt and A. Pohorille, Chem. Rev., 102, 2671-2691(2002): "Hydrophobic Effects and Modeling of Biophysical Aqueous Solution Interfaces"

103. P. Grabowski, D. Riccardi, M. A. Gomez, D. Asthagiri, and L. R. Pratt, J. Phys. Chem. A 106, 9145 (2002): "Quasi-chemical Theory and the Standard Free Energy of $\mathrm{H}^{+}(\mathrm{aq})$ "

104. M. E. Paulaitis and L. R. Pratt, Adv. Prot. Chem. 62, 283-310(2002): "Hydration Theory for Molecular Biophysics"

105. M. Eikerling, S. J. Paddison, L. R. Pratt, and T. A. Zawodzinski, Jr., Chem. Phys. Letts. 368, 108-114 (2003): "Defect Structure for Proton Transport in Triflic Acid Monohydrate Solid"

106. D. Asthagiri and L. R. Pratt Chem. Phys. Letts. 371, 613-619 (2003): "Quasi-Chemical Studies of $\mathrm{Be}^{2+}$ Speciation in Water"

107. H. S. Ashbaugh, D. Asthagiri, L. R. Pratt, and S. B. Rempe, Biophys. Chem. 105, 321336(2003): "Hydration of Krypton and Consideration of Clathrate Models of Hydrophobic Effects from the Perspective of Quasi-Chemical Theory"

108. L. R. Pratt, in THEORY IN ACTION: HIGHLIGHTS IN THE THEORETICAL DIVISION AT LOS ALAMOS 1943-2003, LA-14000-H (history report unclassified): "Modeling and Molecular Theory of Liquids"

109. D. Asthagiri, L. R. Pratt, H. S. Ashbaugh J. Chem. Phys. 119, $2702-2708$ (2003): "Absolute Hydration Free Energies of Ions, Ion-Water Clusters, and Quasi-chemical Theory"

110. L. R. Pratt and H. S. Ashbaugh, Phys. Rev. E 68, 021505 (2003): "Self Consistent Molecular Field Theory for Packing in Classical Liquids"

111. D. Asthagiri, L. R. Pratt, J. D. Kress, and M. A. Gomez, Chem. Phys. Letts. 380, 530-535 (2003): "The hydration state of $\mathrm{HO}^{-}(\mathrm{aq})$ "

112. D. Asthagiri, L. R. Pratt, J. D. Kress Phys. Rev. E 68, 041505 (2003): "Free Energy of Liquid Water on the Basis of Quasi-Chemical Theory and Ab Initio Molecular Dynamics"

113. R. A. LaViolette, K. L. Copeland, and L. R. Pratt, J. Phys. Chem. A 107, 11267 (2003): "Cages of Water Coordinating Kr in Aqueous Solution"

114. D. Asthagiri, L. R. Pratt, M. E. Paulaitis, and S. B. Rempe, J. Am. Chem. Soc. 126, 12851289(2003): "Hydration Structure and Free Energy of Biomolecularly Specific Aqueous Dications, including $\mathrm{Zn}^{2+}$ and First-Transition-Row Metals"

115. S. B. Rempe, D. Asthagiri, L. R. Pratt, PCCP 6, 1966-1969 (2004): "Inner Shell Definition and Absolute Hydration Free Energy of $\mathrm{K}^{+}(\mathrm{aq})$ on the Basis of Quasi-chemical Theory and Ab Initio Molecular Dynamics."

116. D. Asthagiri, L. R. Pratt, J. D. Kress, M. A. Gomez Proc. Natl. Acad. Sci USA 101, 72297233(2004): "Hydration and Mobility of $\mathrm{HO}^{-}$(aq)"

117. H. S. Ashbaugh, L. R. Pratt, M. E. Paulaitis, J. Clohecy, and T. L. Beck, J. Am. Chem. Soc. 127, 2808 - 2809 (2005): "Deblurred observation of the molecular structure of an oil-water interface"

118. D. Asthagiri, L. R. Pratt, and J. D. Kress, Proc. Natl. Acad. Sci USA 102, 6704-6708(2005): "Ab initio molecular dynamics and quasichemical study of $\mathrm{H}^{+}(\mathrm{aq})$ "

119. H. S. Ashbaugh and L. R. Pratt, Rev. Mod. Phys. 78, 159-178(2006): "Scaled-particle theory and the length scales of hydrophobicity" See also: February 1, 2006 issue of Virtual Journal of Biological Physics Research, and February 13, 2006 issue of Virtual Journal of Nanoscale Science Es Technology.

120. A. Paliwal, D. Asthagiri, L. R. Pratt, H. S. Ashbaugh, M. E. Paulaitis, J. Chem. Phys. 124, 224502(2006): "An analysis of molecular packing and chemical association in liquid water using quasi-chemical theory" 
121. D. Asthagiri, L. R. Pratt, and M. E. Paulaitis, J. Chem. Phys. 125, 124701(2006): "Role of fluctuations in a snug-fit mechanism of KcsA channel selectivity" See also July 15, 2006 issue of Virtual Journal of Biological Physics Research.

122. T. L. Beck, M. E. Paulaitis, and L. R. Pratt Cambridge University Press (2006): THE POTENTIAL DISTRIBUTION THEOREM AND MODELS OF MOLECULAR SOLUTIONS.

123. L. R. Pratt and D. Asthagiri, in FREE ENERGY CALCULATIONS. THEORY AND APPLICATIONS IN CHEMISTRY AND BIOLOGY, Springer Series in Chemical Physics, Vol. 86 (2007), Chipot, C.; Pohorille, Andrew (Eds.): "Potential distribution methods and free energy models of molecular solutions"

124. M. A. Gomez, L. R. Pratt, J. D. Kress, and D. Asthagiri, Surf. Sci. 601, 1608-1614(2007): "Water adsorption and dissociation on BeO (001) and (100) surfaces"

125. H. S. Ashbaugh and L. R. Pratt, J. Phys. Chem. B 111, 9330 - 9336(2007): "Contrasting non-aqueous against aqueous solvation on the basis of scaled-particle theory"

126. T. M. McCleskey, D. S. Ehler, T. S. Keizer, D. N. Asthagiri, L. R. Pratt, R. Michalczyk, and B. L. Scott, Angew. Chemie - Int. Ed. 46, 2669 - 2671, (2007): "Beryllium displacement of $\mathrm{H}^{+}$ from strong hydrogen bonds"

127. D. Asthagiri, H. S. Ashbaugh, A. Piryatinski, M. E. Paulaitis, and L. R. Pratt, J. Am. Chem. Soc. 129, 10133 - 10140 (2007): "Non-van der Waals treatment of the hydrophobic solubility of $\mathrm{CF}_{4} "$

128. J. K. Shah, D. Asthagiri, L. R. Pratt, and M. E. Paulaitis, J. Chem. Phys. 127, 144508 (2007): "Balancing local order and long-ranged interactions in the molecular theory of liquid water"

129. S. Chempath, B. R. Einsla, L. R. Pratt, C. S. Boncella, J. M. Macomber, J. A. Rau, and B. S. Pivovar, J. Phys. Chem. C 112, 3179 - 3182 (2008): "Mechanism of tetraalkylammonium headgroup degradation in alkaline fuel cell membranes"

130. D. Asthagiri, S. Merchant, L. R. Pratt, J. Chem. Phys. 128, 244512 (2008): "Role of attractive methane-water interactions in the potential of mean force between methane molecules in water" Selected for the July 1, 2008 issue of Virtual Journal of Biological Physics Research.

131. S. Chempath and L. R. Pratt, J. Phys. Chem. B 113, 4147-4151(2009): "Distribution of binding energies of a water molecule in the water liquid-vapor interface"

132. S. Chempath, L. R. Pratt, and M. E. Paulaitis, J. Chem. Phys. 130, 054113 (2009): "Quasichemical theory with a soft cutoff"

133. L. Yang, B. H. Fishbine, A. Migliori, and L. R. Pratt, J. Am. Chem. Soc. 131, 1237312376 (2009): "Molecular simulation of electric double-layer capacitors based on carbon nanotube forests"

134. P. Zhu, T. Harris, M. Driver, C. Campbell, L. R. Pratt, K. Papadopoulos, J. Phys. Chem. $C, 113,16458-16463$ (2009): 'Dissolution Kinetics of [Hmim][BF 4 ] Ionic Liquid Droplets in 1Pentanol"

135. D. Asthagiri, P. D. Dixit, S. Merchant, M. E. Paulaitis, L. R. Pratt, S. B. Rempe, and S. Varma, Chem. Phys. Letts. (Frontier Article with cover graphics) 485, 1-7 (2010): "Ion selectivity from local configurations of ligands"

136. L. Yang, B. H. Fishbine, A. Migliori, L. R. Pratt, J. Chem. Phys. 132, 044701(2010): "Dielectric saturation of liquid propylene carbonate in electrical energy storage applications" See also: February 1, 2010 issue of Virtual Journal of Nanoscale Science 83 Technology.

137. S. Chempath, L. R. Pratt and M. E. Paulaitis, Chem. Phys. Letts., 487, 24-27(2010): "Distributions of extreme contributions to binding energies of molecules in liquids"

138. A. C. Beveridge, J. H. Jett, R. A. Keller, L. R. Pratt, and T. M. Yoshida, Analyst, 135, 13331338(2010): "Reduction in Diffusion Broadening in Flow Experiments by Analysis of Time-Gated Single-Molecule Data" 
139. S. Chempath, J. M. Boncella, L. R. Pratt, N. Henson, B. S. Pivovar, J. Phys. Chem. C, 114, 11977-11983(2010): "Density functional theory study of degradation of tetraalkylammonium hydroxides"

140. M. I. Chaudhari, L. R. Pratt, and M. E. Paulaitis, J. Chem. Phys., 133 231102(2010): "Direct observation of a hydrophobic bond in loop-closure of a capped $\left(-\mathrm{OCH}_{2} \mathrm{CH}_{2}-\right)_{n}$ oligomer in water"

141. P. Zhu, X. You, L. R. Pratt, and K. D. Papadopoulos, J. Chem. Phys., 134 054502(2011): "Generalizations of the Fuoss Approximation for Ion Pairing"

142. L. J. Thibodeaux, K. T. Valsaraj, V. T. John, K. D. Papadopoulos, L. R. Pratt, and N. S. Pesika, Environmental Engineering Science, 28 87-93(2011): "Marine Oil Fate: Knowledge Gaps, Basic Research, and Development Needs; A Perspective Based on the Deepwater Horizon Spill"

143. S. Varma, D. M. Rogers, L. R. Pratt, and S. B. Rempe, J. Gen. Physiol. 137, 479-488 (2011): "Design principles for $\mathrm{K}^{+}$selectivity in membrane transport"

144. M. Hamsa Priya, L. R. Pratt, and M. E. Paulaitis, Langmuir 27, 13713-13718 (2011): "Effect of PEG End-Group Hydrophobicity on Lysozyme Interactions in Solution Characterized by Light Scattering"

145. J. D. Weeks and L. R. Pratt, J. Stat. Phys. 145, 207-208(2011): "Introduction to Special Issue on Water and Associated Liquids"

146. D. M. Rogers, D. Jiao, L. R. Pratt, and S. B. Rempe, Ann. Rep. Comp. Chem. 8, 71-128 (2012): "Structural Models and Molecular Thermodynamics of Hydration of Ions and Small Molecules"

147. A. Pohorille and L. R. Pratt, Origin of Life and Evolution of Biospheres 42, (2012): "Is Water the Universal Solvent for Life?" [See also: L. R. Pratt, A. Pohorille, and D. Asthagiri, http://arxiv.org/abs/physics/0701282: "What is special about water as a matrix of life?"]

148. P. Zhu, L. R. Pratt, and K. D. Papadopoulos, J. Chem. Phys. 137, 174501(2012): "Pairing of 1-hexyl-3-methylimidazolium and tetrafluoroborate ions in $n$-pentanol"

149. X. You, M. I. Chaudhari, L. R. Pratt, N. Pesika, K. M. Aritakula, and S. W. Rick, J. Chem. Phys. 138, 114708 (2013): "Interfaces of Propylene Carbonate"

150. D. Sabo, D. Jiao, S. Varma, L. R. Pratt, and S. B. Rempe, Annu. Rep. Prog. Chem. Soc. $C$ (2013): "Case study of $\mathrm{Rb}^{+}(\mathrm{aq})$, quasi-chemical theory of ion hydration, and the no split occupancies rule" DOI: 10.1039/C3PC90011H [See also: http://arxiv.org/abs/1303.3210 .]

151. M. I. Chaudhari, S. Holleran, H. S. Ashbaugh, and L. R. Pratt, Proc. Natl. Acad. Sci. USA 110, 20557-20562 (2013): "Molecular-scale Hydrophobic Interactions between Hard-sphere Reference Solutes are Attractive and Endothermic" (See also: http://arxiv.org/abs/1303.6597v1.)

152. W. Zhang, X. You, and L. R. Pratt, J. Phys. Chem. B 118, 7730-7738 (2013): "Multi-scale theory in the molecular simulation of electrolyte solutions"

153. X. You, M. I. Chaudhari, and L. R. Pratt, AQUA INCOGNITA, pp. 434-442, editors B. W. Ninham and P. Lo Nostro (Connor Court Publishing Pty Ltd., 2014): "Comparison of Mechanical and Thermodynamical Evaluations of Electrostatic Potential Differences between Electrolyte Solutions"

154. M. I. Chaudhari and L. R. Pratt, OIL SPILL REMEDIATION: COLLOID CHEMISTRYBASED PRINCIPLES AND SOLUTIONS, pp. 247-257, editors P. Somasundaran, R. S. Farinato, P. Patra, and K. Papadopoulos (John Wiley \& Sons, Hoboken New Jersey, 2014): "Microstructures of capped ethylene oxide oligomers in water and n-hexane."

[See: http://arxiv.org/abs/1303.6597 and https://dx.doi.org/10.6084/m9.figshare.3123898.v1. ]

155. M. I. Chaudhari, L. R. Pratt, and M. E. Paulaitis, J. Phys. Chem. B (2014): "Loop-Closure and Gaussian Models of Collective Structural Characteristics of Capped PEO Oligomers in Water" DOI: $10.1021 / j p 504244 x$

156. M. I. Chaudhari, D. Sabo, L. R. Pratt, and S. B. Rempe, J. Phys. Chem. B (2014): "Hydration of $\mathrm{Kr}(\mathrm{aq})$ in dilute and concentrated solutions" DOI: 10.1021/jp508866h 
157. M. I. Chaudhari, L. R. Pratt, and M. E. Paulaitis, J. Chem. Phys. 141, 244908 (2014): "Concentration dependence of the Flory-Huggins interaction parameter in aqueous solutions of capped PEO chains" http://dx.doi.org/10.1063/1.4904386

158. L. R. Pratt Encyclopedia of Astrobiology, Springer-Verlag, Berlin (2014): "Hydrophobic Effect," DOI 10.1007/978-3-642-27833-4_704-3

159. X. You, L. R. Pratt, and S. W. Rick: "The role of attractive interactions in the dynamics of molecules in liquids," arXiv:1411.1773 [physics.chem-ph] (2014)

160. W. Zhang and L. R. Pratt, Electrochem. Soc. Trans. 66, 1-5 (2015): "AIMD Results for a Concentrated Solution of Tetra-ethylammonium Tetra-fluoroborate in Propylene Carbonate"

161. X. You, M. I. Chaudhari, S. B. Rempe, and L. R. Pratt, Electrochem. Soc. Trans., 69, 107-111 (2015): "Dielectric Properties of Ethylene Carbonate and Propylene Carbonate using Molecular Dynamics Simulations"

162. X. You, M. I. Chaudhari, S. B. Rempe, and L. R. Pratt, J. Phys. Chem. B (2015): "Dielectric Relaxation of Ethylene Carbonate and Propylene Carbonate from Molecular Dynamics Simulations" (DOI: 10.1021/acs.jpcb.5b09561)

163. M. I. Chaudhari, S. B. Rempe, D. Asthagiri, and L. Tan, L. R. Pratt, J. Phys. Chem. B (2015): "Molecular Theory and the Effects of Solute Attractive Forces on Hydrophobic Interactions" (DOI: 10.1021/acs.jpcb.5b09552)

164. L. R. Pratt, M. I. Chaudhari, and S. B. Rempe, J. Phys. Chem. B (2016): "Statistical Analyses of Hydrophobic Interactions: A Mini-Review" (DOI: 10.1021/acs.jpcb.6b04082)

165. M. I. Chaudhari, J. Nair, L. R. Pratt, F. Soto, P. Balbuena, S. B. Rempe, J. Chem. Theory \& Comp. (2016): "Scaling Atomic Partial Charges of Carbonate Solvents for Lithium Ion Solvation and Diffusion" (DOI: 10.1021/acs.jctc.6b00824)

166. M. Oguntoye, M. Johnson, L. R. Pratt, N. S. Pesika, ACS Applied Materials \& Interfaces 8, 27454-27457 (2016): "Triboelectricity Generation from Vertically Aligned Carbon Nanotube Arrays"

167. M. I. Chaudhari, L. R. Pratt, and S. B. Rempe, Molecular Simulation (2017): "Utility of Chemical Computations in Predicting Solution Free Energies of Metal Ions" (DOI: 10.1080/08927022.2017.1342127)

168. A. Muralidharan, M. I. Chaudhari, S. B. Rempe, and L. R. Pratt, Electrochem. Soc. Trans. 77, 1155-1162 (2017): "Molecular Dynamics Simulations of Lithium Ion Transport through a Model Solid Electrolyte Interphase (SEI) Layer"

169. M. I. Chaudhari, S. B. Rempe, and L. R. Pratt, J. Chem. Phys. 147, 161728(2017): "Quasichemical Theory of $\mathrm{F}^{-}(\mathrm{aq})$ : The 'no split occupancies rule' revisited" (DOI: 10.1063/1.4986244)

170. L. Pashazanusi, M. Oguntoye, S. Oak, J. N. L. Albert, L. R. Pratt, N. Pesika, Langmuir 34, 801-806 (2017): "Anomalous Potential Dependent Friction on $\mathrm{Au}(111)$ measured by AFM"

171. L. Tan, L. R. Pratt and M. I. Chaudhari, J. Phys. Chem. B, (2017) DOI: acs.jpcb.7b10336: "Molecular-scale Description of SPAN80 Desorption from the Squalane-Water Interface" (arXiv:1603.04033v1, [physics.chem-ph, see also DOI: 10.6084/m9.figshare.3114928]

172. M. I. Chaudhari, A. Muralidharan, L. R. Pratt, and S. B. Rempe, Top. Curr. Chem. 376, 7 (2018): "Assessment of Simple Models for Molecular Simulation of Ethylene Carbonate and Propylene Carbonate as Solvents for Electrolyte Solutions"

173. A. Muralidharan, L. R. Pratt, M. I. Chaudhari, and S. B. Rempe, J. Chem. Phys. 148, 2228216(2018): "Comparison of Single-Ion Molecular Dynamics in Common Solvents"

174. A. Muralidharan, L. R. Pratt, G. G. Hoffman, M. I. Chaudhari, and S. B. Rempe, ChemSusChem 11, (2018), DOI 10.1002/cssc.201800323: "Molecular Simulation Results on Charged CarbonNanotube Forest Supercapacitors"

175. A. Gao, L. Tan, M. I. Chaudhari, D. Asthagiri, L. R. Pratt, S. B. Rempe, and J. D. Weeks J. Phys. Chem. B (2018): "The Role of Solute Attractive Forces in the Atomic-Scale Theory of Hydrophobic Effects." (10.1021/acs.jpcb.8b01711) 
176. A. Muralidharan, M. I. Chaudhari, S. B. Rempe, and L. R. Pratt, Sci. Reports 8, 10736 (2018): "Molecular Dynamics Simulations of Lithium Ion Transport in a Model Solid Electrolyte Interphase (SEI) Layer"

177. A. Muralidharan, L. R. Pratt, M. I. Chaudhari, and S. B. Rempe J. Phys. Chem. A, acs.jpca.8b084747, (2018): "Quasi-Chemical Theory with Cluster Sampling from Ab Initio Molecular Dynamics: Fluoride Anion Hydration $\left(\mathrm{F}^{-}\right)$"

178. A. Muralidharan, L. R. Pratt, M. I. Chaudhari, and S. B. Rempe Chem. Phys. Letts., Frontiers Article (2019) https://doi.org/10.1016/j.cpletx.2019.100037: "Quasi-Chemical Theory for Anion Hydration and Specific Ion Effects: $\mathrm{Cl}^{-}(\mathrm{aq})$ vs. $\mathrm{F}^{-}(\mathrm{aq})$ "

179. M. I. Chaudhari, J. M. Vanegas, A. Muralidharan, L. R. Pratt, and S. B. Rempe Ann. Rev. Phys. Chem. 71, 461-484 (2020): "Hydration Mimicry by Membrane Ion Channels." arXiv:1812.06913v1 [physics.chem-ph] (2019)

180. D. S. Tomar, M. E. Paulaitis, L. R. Pratt, and D. Asthagiri arXiv:1812.06913v1 [physics.chem-ph] (2018): "Long-Range Interactions Dominate the Inverse-Temperature Dependence of Polypeptide Hydration Free Energies"

181. L. R. Pratt, D. Asthagiri, and S. B. Rempe, LA-UR-05-5986: "Momentum truncation errors and inferences of $\mathrm{Li}^{+}$hydration number on the basis of neutron diffraction from aqueous solutions" 